\title{
The DiSSCo Knowledgebase: A trusted information hub for the natural science collection community worldwide
}

\author{
Mareike Petersen ${ }^{\ddagger}$, Sabine von Mering ${ }^{\ddagger}$, Julia Pim Reis ${ }^{\ddagger}$, Falko Glöckler ${ }^{\ddagger}$ \\ ‡ Museum für Naturkunde Berlin, Leibniz Institute for Evolution and Biodiversity Science, Berlin, Germany
}

Corresponding author: Mareike Petersen (mareike.petersen@mfn.berlin)

Received: 03 Sep 2021 | Published: 03 Sep 2021

Citation: Petersen M, von Mering S, Pim Reis J, Glöckler F (2021) The DiSSCo Knowledgebase: A trusted information hub for the natural science collection community worldwide. Biodiversity Information Science and Standards 5: e73900. https://doi.org/10.3897/biss.5.73900

\begin{abstract}
In the last two decades, various projects and initiatives have conducted research on how to share, exchange, and link information from natural science collection objects. This profound (technical) knowledge, standards, tools, and best practices are essential to the development of any new research infrastructure facilitating research on bio- and geodiversity. However, the knowledge and research results are usually not easily accessible at a single point and particularly not in a well-curated form. Here, the Knowledgebase developed for the Distributed System of Scientific Collections (DiSSCo) comes into play. This information hub will act as trusted source for project outcomes and other relevant resources (e.g., web services, Persistent Identifier Systems, controlled vocabularies, domain-specific ontologies and standards) for users and developers of DiSSCo and other research infrastructures worldwide. In this talk, we will present the current version of the DiSSCo Knowledgebase, its developmental approach, and the opportunity for this source to act as an e-service for various stakeholder groups interested in and working with natural science collections worldwide.
\end{abstract}

\section{Keywords}

research infrastructure, common resources, e-service 


\section{Presenting author}

Mareike Petersen

\section{Presented at}

TDWG 2021 